\title{
aniki
}

Revista Portuguesa da Imagem em Movimento

Portuguese Journal of the Moving Image

\section{Analisar a Materialidade no Cinema Português: Estéticas e práticas}

\author{
Caterina Cucinotta \\ Instituto de História Contemporânea da Universidade NOVA de Lisboa \\ caterinacucinotta@fcsh.unl.pt \\ https://orcid.org/0000-0002-0572-6930
}

\section{Federico Pierotti}

Università degli studi di Firenze UniFi federico.pierotti@unifi.it

https://orcid.org/0000-0003-1021-5948

RESUMO Texto de introdução ao dossier temático da autoria dos editores convidados Caterina Cucinotta e Federico Pierotti. Os autores situam o seu contributo no quadro do materialist turn que se tem feito sentir, em várias disciplinas, nos últimos vinte anos, para propor uma abordagem ao cinema português que dedica particular atenção aos conceitos de materialidade, estética fílmica e práticas cinematográficas. Os cinco ensaios do dossier são apresentados à luz dos três tipos de materialidade identificados pelo arqueólogo dos média Jussi Parikka: a materialidade da prática cultural; a materialidade dos materiais; e a materialidade da tecnologia. O resultado é um programa fértil que promete assegurar o futuro dos estudos da materialidade no cinema português.

PALAVRAS-CHAVE Cinema português; materialidade; materialist turn; arqueologia dos média.

Nos vinte anos que decorreram entre a publicação de Simulacros $e$ Simulação, de Jean Baudrillard, em 1981, e o lançamento de The Matrix, de Andy e Larry Wachowski, em 1999 - no último, a versão inglesa do livro é visível no início do filme - tornou-se consciente uma interpretação do digital como virtualidade, abstração e perda de realidade. Hoje, em tempos de crises ambientais e pandémicas, novas distopias vêm substituir as antigas. Aprendemos que inúmeras operações intangíveis já diziam respeito aos velhos média e que o 
digital não é, de forma alguma, alheio à dimensão material (Dias Branco 2019).

Nas últimas duas décadas, uma série de estudos, inspirados em paradigmas neo-materialistas, concentrou a atenção na dimensão tecnológica subjacente aos processos de digitalização e circulação de dados. De acordo com Jussi Parikka, "the recent years of culturaltheoretical debate have seen a renewed interest in matter, objects, material processes and the posthuman and non-human" $(2012,84)$. Neste novo impulso das teorias materialistas dos média, o estudo sistemático de hardware e infraestruturas tem contribuído, de forma decisiva, para uma releitura do mundo em que vivemos a partir de um maior enfoque na dimensão tecnológica dos média, à custa dos conteúdos por estes veiculados. As redes digitais e as conexões que os média possibilitam não têm apenas a ver com tecnologia e ciência, mas também com aspetos históricos, económicos, culturais, geopolíticos, militares, logísticos e ambientais (Peters 2015, 13-52; Parks e Starosielski 2015; Starosielski 2015, xi-xiv).

Em comparação com o debate pós-moderno sobre o digital, as ameaças que inquietam a opinião pública mudaram e tornaram-se mais concretas, materiais, tangíveis. Em geral, um materialist turn acabou por permear uma pluralidade de disciplinas, convidando estudiosos de história, antropologia, história da arte, história da ciência, literatura e estudos culturais para lidar com as várias formas de materialidade envolvidas nos diferentes campos de pesquisa (Brown 2010, 50). Tratase de uma materialidade entendida como algo mais do que apenas matéria, como: "an excess, force, vitality, relationality, or difference that renders matter active, self-creative, productive, unpredictable" (Coole-Frost 2010, 9). Desta forma, o interesse imposto pela cultura material pressionou os investigadores de várias disciplinas para porem em prática "more materialist modes of analysis and [...] new ways of thinking about matter and processes of materialization" (Coole-Frost 2010, 2).

Nos últimos anos, a arqueologia dos média também tem mostrado particular interesse na materialidade e na tecnologia, colocando o presente e o passado em relação dialética, através de perspetivas interessadas em estudar a transição da obsolescência para a remediação ("the old in the new") ou em destacar o tempo profundo na base de cada configuração medial ("the new in the old") (Strauven 2013, 6771). Tal cenário leva-nos a querer rever as ferramentas para o estudo 
do cinema, a partir das diferentes ideias de materialidade que podem emergir.

Muitas são as reflexões possíveis a partir do conceito de materialidade em relação ao cinema: o que é (ontologia); que saberes é capaz de produzir, articular, comunicar (epistemologia); que formas pode sustentar (esteticamente), e assim por diante. Para os fins do dossier "Materialidades no Cinema Português: Estéticas, práticas e técnicas", que nos propusemos a organizar para a Aniki, parece-nos útil partir da tipologia proposta pelo arqueólogo dos média Jussi Parikka (2012, 1634), que identifica três tipos de materialidade: (1) a materialidade da prática cultural, que diz respeito aos aspetos materiais das atividades humanas; (2) a materialidade dos materiais, que coloca o problema do impacto social e ecológico dos materiais; (3) a materialidade da tecnologia, linha preferida da teoria alemã dos média, que favorece a investigação acerca do funcionamento da tecnologia. Ao trasladar esses três conceitos para a investigação do cinema, identifica-se um possível percurso para os estudos sobre cinema e materialidade, que procuraremos desenvolver de seguida, ainda que de forma breve.

(1) A materialidade da prática cultural. Este primeiro caminho leva-nos a considerar o cinema como uma prática cultural material na qual interagem diferentes objetos, técnicas e saberes. O estudo da materialidade do cinema empenha-se em observar os vários elementos que constroem o filme com o objetivo de valorizar a génese dos processos criativos aí implicados (Salles de Almeida 2008). Ao desmontar e ao isolar as diferentes componentes materiais, é possível perceber melhor a natureza do filme como objeto complexo, que nasce da montagem de ações únicas e atos concretos. Como Raymond Williams já observara na década de 1970:

\footnotetext{
Yet painters and sculptors remained manual workers. Musicians remained involved with the material performance and material notation in instruments which were the products of conscious and prolonged manual skills. Dramatists remained involved with the material properties of stages and the physical properties of actors and voices. Writers [...] handled material notations on paper. Necessarily, inside any art, there is this physical and material consciousness. (Williams 1977, 162)
}

Isso aplica-se ainda mais ao cinema, cuja materialidade pode ser estudada em todas as práticas e técnicas que entram em jogo na pré- 
produção, produção e pós-produção de um filme: argumento, casting, repérage, produção de cenários, vestuário e adereços, imagem, iluminação, captura de som, acompanhamento musical, mistura, etc. Estes ofícios 'interartísticos' têm sido frequentemente colocados de parte, em benefício de uma conceção que vê o realizador como o único e exclusivo responsável do filme. Pelo contrário, definições, como as de Peter Kubelka, de criação cinematográfica como "a tailor's work in progress" (Korossi 2016) devolvem o merecido espaço a estes ofícios. Juntamente com esta cultura material de produção, podemos considerar uma outra mais ligada ao consumo, que diz respeito aos lugares de fruição (ex. salas de cinema, festivais, cineclubes, associações) e aos materiais efémeros que lhes estão associados (ex. cartazes, postais, programas de sala, fotografias, recortes, gadgets). Se analisarmos estes elementos, enriqueceremos a história do cinema, com tantas micro-histórias ainda por contar. São sobretudo histórias dedicadas a objetos, lugares e corpos que interagem entre si.

(2) A materialidade dos materiais. Este segundo conceito leva-nos a pensar o cinema a partir dos diversos tipos de materiais que nele estão envolvidos - das rochas aos tecidos, da madeira ao plástico. Materiais esses que, não só fazem parte da história material do filme, mas que, em muitos casos, sustentam práticas criativas e poéticas significativas, como a "estética dos materiais" de António Reis, a que voltaremos em breve.

(3) A materialidade da tecnologia. Por fim, este último conceito remete o foco para os aspetos tecnológicos que estão no medium, convidandonos a estudar as suas máquinas e equipamentos. O cinema é, naturalmente, um mecanismo complexo que implica a utilização de inúmeras máquinas e tecnologias, ligadas tanto à área da gravação e da representação audiovisual (câmaras e projetores, microfones e altifalantes, hardware e software de pós-produção, correção de cor, mistura de som, etc.) quanto a uma área implícita e tradicionalmente negligenciada (geradores, laboratórios de impressão, sistemas de distribuição, logística e armazenamento, redes e infraestruturas de suporte à circulação de filmes, etc.), mas destinada a adquirir centralidade face ao crescente interesse pela ecologia dos média.

Voltando ao dossier aqui apresentado, embora se enquadre nas temáticas que acabámos de delinear, ele abrange uma área mais limitada. Os cinco ensaios que o compõem podem ser reconduzidos a uma interseção entre a primeira e a segunda categoria. Inspirando-se 
principalmente na análise fílmica, os seus autores utilizam metodologias e ferramentas de investigação da materialidade que evidenciam as possíveis ligações entre as poéticas e as estéticas do cinema português.

Entre as várias ligações que nos sugerem estes ensaios, um lugar de destaque merece ser atribuído aos filmes de Margarida Cordeiro e António Reis. Em 1989, foi o próprio Reis que lançou a ideia de uma “estética dos materiais”, para destacar significados novos e profundos a partir da matéria bruta da qual são feitos os filmes. Durante a estreia portuguesa de Rosa de Areia, o realizador definiu-o como um filme onde se joga "com os materiais mais duros e puros, desde a rocha granítica e basáltica, à areia” (Cautela 1997, 235) e, ainda, como "um filme de matérias: matérias em permanente devir" (Matos Silva 1997, 279). A partir desta ideia, é possível delinear as genealogias e as projeções futuras desta estética, identificando os seus múltiplos vestígios na história material (e dos materiais) do cinema português.

Visto desta perspetiva, o cinema português representa um caso de particular interesse. Ancorado em práticas artesanais mais fortes, quando comparado a outras cinematografias, atribuiu desde sempre uma importância central à materialidade. Ao olhar para o cinema português de um ponto de vista material, permitimos uma viragem na análise, onde se descobrem a complexidade material da obra e das suas circunstâncias criativas, as relações fílmicas que o espectador deve interpretar e as condições materiais da paisagem fiśico-politica onde atuam. De facto, quando a dramaturgia narrativa aparece relacionada com a materialidade abrem-se vários caminhos à volta de elementos cruciais para uma construção fílmica diferente. As imagens em movimento juntam-se aos sons para dar vida a significações complexas que, nas relações entre materialidade e imaterialidade, transbordam o seu valor simbólico para adquirir força num sentido mais amplo (Melo Ferreira 2011).

Nota-se, nestes cinco artigos, uma urgência em fazer uma recapitulação de algumas das obras peculiares para "uma história do cinema português" (Cunha, 2018), a partir de perspetivas pouco exploradas, como a música, os atores, a montagem, entre outras. Retorna, no autor e nas autoras destes ensaios, a questão do uso da estética fílmica como agente que produz uma variável estável nas modalidades de produção. Mais do que isso, figuras emblemáticas do cinema português são tomadas como referências necessárias para uma construção do gesto 
político, que passa, inevitavelmente, pela estética. Estas novas formas de pensar o espaço fílmico na sua materialidade vêm com o propósito de estabelecer uma reflexão acerca do futuro do cinema, na relação deste com as análises dos filmes. É uma tentativa de aproximação entre as práticas e as teorias fílmicas, tendo como objetivo uma sempre maior inclusão daqueles elementos pouco valorizados, mas cruciais, numa construção "from below" das histórias do cinema.

Os artigos aqui reunidos mostram uma certa tendência para a análise de elementos separados: nas palavras de Mariana Cunha e Catarina Andrade, a materialidade do cinema é abordada como "um prisma", a fim de revelar aspetos formais que constroem interessantes percursos teóricos. Neste primeiro ensaio, "Devolver a história, materializar o trauma: Observações sobre os corpos migrantes em Cavalo Dinheiro (2014) e Vitalina Varela (2019), de Pedro Costa”, as duas autoras analisam as duas últimas longas-metragens de Pedro Costa sob a perspetiva de uma biopolítica da materialidade. A análise é confrontada com diferentes ideias de materialidade: a do aparato digital adotado pelo realizador desde No Quarto da Vanda (2000); a da imagem e das suas operações formais na elaboração da memória histórica (estética da imobilidade; monumentalização das personagens); a dos corpos patológicos e diaspóricos de Ventura e Vitalina, que expressam a condição pós-traumática de um corpo social inteiro carregado e marcado pelas feridas permanentes do colonialismo.

No ensaio seguinte, "Materialidade e materialismo em Scenes from the Class Struggle in Portugal (1977-79), de Robert Kramer e Philip Spinelli”, da autoria de Raquel Schefer, a materialidade torna-se uma categoria histórica declinada à luz do debate sobre o cinema militante dos anos 1970. A autora examina Scenes from the Class Struggle in Portugal, um dos mais importantes filmes sobre a revolução portuguesa de 1974. No filme, de produção norte-americana, imbricam-se uma representação crítica e analítica da revolução e uma proposta em linha com as principais tendências do cinema revolucionário português, particularmente no que diz respeito à tensão entre engajamento político e experimentação formal. Schefer vê-o como um filme que evidencia uma forma de cinema materialista e dialético, seguindo a acepção de Jean-Paul Fargier, que utiliza sistematicamente formas multitemporais e fragmentárias para desconstruir os mecanismos da impressão de realidade. 
No terceiro ensaio, "Materialidade e Desejo de Ficção: A canção em quatro 'momentos musicais' do cinema de Miguel Gomes”, a música é o elemento escolhido para mostrar conexões inesperadas entre a esfera política e o mundo emocional. Inspirada nos métodos dos sound studies e dos film music studies, Agnès Pellerin propõe uma leitura original do cinema de Miguel Gomes como fábrica de canções, que derruba sistematicamente a hierarquia entre imagem e som a que estamos habituados. Matéria-prima de Aquele Querido Mês de Agosto (2008), as canções mantêm a sua importância também nos filmes seguintes, Tabu (2012) e As Mil e Uma Noites (2015), continuando a revelar verdades emocionais, ao mesmo tempo que veiculam ambivalências ideológicas. Enquadrando-se na história do cinema cantado, os filmes de Gomes apresentam um tratamento particularmente original e rico da materialidade da canção. Através da análise de quatro exemplos, a autora revela como as canções, além dos seus sentidos representativos, suspendem o tempo da narração e cristalizam o "desejo de ficção" do espectador.

Juntamente com a música, a montagem é a forma mais adequada de relacionar os materiais heterogéneos convocados pelos filmes, como nos lembram os dois últimos ensaios deste dossier. Em "Vidros Partidos (2012), de Víctor Erice: Una poética del montaje”, Jesús Ramé López examina a poética da montagem de Vidros Partidos, uma curtametragem que integra o filme de produção portuguesa Centro Histórico (Victor Erice, Pedro Costa, Manoel de Oliveira, Aki Kaurismäki, 2012). O filme é composto por diferentes entrevistas com pessoas que tiveram uma relação laboral com uma fábrica no norte de Portugal e que refletem um contexto de produção que o capitalismo cognitivo fez desaparecer. A partir da "estética dos materiais" teorizada por António Reis, o artigo investiga o papel da montagem no processo criativo, analisando os modos de relação que se geram entre os materiais organizados em unidades tonais nas suas diferentes partes para, assim, criar uma unidade total de discurso.

Teresa Biondi, no artigo intitulado "The Aesthetics of 'Speaking Objects' in Aniki-Bóbó's Anthropo-cosmo-morphic Material”, também se foca no papel da montagem, concluindo o dossier com uma análise de Aniki-Bóbó (Manoel de Oliveira, 1942). Este grande clássico do cinema português é reinterpretado à luz das categorias da antropologia sociológica de Edgar Morin (1980). Especificamente, a autora examina o papel dos corpos, lugares e objetos, mostrando como Oliveira 
implementa um processo de re-semantização narrativa a formas atribuíveis à montagem intelectual. Desse modo, os materiais do filme tornam-se partes interligadas de uma articulação metafórica que se realiza por meio do cosmo-morfismo do homem e do antropomorfismo dos objetos.

As perspetivas que emergem dos cinco ensaios acolhidos neste dossier não conseguem, evidentemente, esgotar um campo de investigação que - como já foi mencionado - permanece extremamente rico e complexo, fecundo e promissor. Para o futuro dos estudos da materialidade no cinema português, o programa continua fértil. Para além dos horizontes estabelecidos e canonizados do cinema de autor, várias direções permanecem por investigar - do cinema popular ao cinema de não ficção e aos 'outros filmes' - cine-jornais, filmes turísticos, filmes industriais (Sampaio, Schefer e Blank 2016). São inúmeras as matérias-primas que ficam a aguardar os investigadores do cinema português.

\section{Referências}

Baudrillard, Jean. 1991. Simulacros e Simulação. Tradução de Maria João da Costa Pereira. Lisboa: Relógio d'Água.

Brown, Bill. 2010. "Materiality”. Em Critical Terms for Media Studies, editado por W.J.T. Mitchell e Mark B.N. Hansen, 49-63. Chicago e Londres: The University of Chicago Press.

Cautela, Afonso. 1997. "Flor do Deserto nasce no asfalto de Lisboa”. Em António Reis e Margarida Cordeiro: A Poesia da Terra, editado por Anabela Moutinho e Maria da Graça Lobo, 235-236. Faro: Cineclube de Faro.

Coole, Diana e Frost, Samantha. 2010. "Introducing the New Materialisms”. Em New Materialisms: Ontology, Agency, and Politics, editado por Diana Coole e Samantha Frost, 1-43. Durham: Duke University Press.

Cunha, Paulo. 2018. Uma Nova História do Novo Cinema Português. Lisboa: Outro Modo/Le Monde Diplomatique.

Dias Branco, Sérgio. 2019. "Digitações. Cinema digital e materialidade”, palestra apresentada à Universidade de Brasília, Faculdade de Comunicação, Instituto de Letras. 
https://www.academia.edu/44961829/Digitações_Cinema_Digit al_e_Materialidade (último acesso a 19 junho 2020).

Korossi, Georgia. 2016. "The Materiality of Film: Peter Kubelka”. Em BFI British Film Institute, https://www.bfi.org.uk/news/materiality-film-peter-kubelka (último acesso a 19 junho 2020).

Matos Silva, Fernando. 1997. "António Reis e Margarida Cordeiro: Entrevista sobre Rosa de Areia.” Em António Reis e Margarida Cordeiro: A Poesia da Terra, editado por Anabela Moutinho e Maria da Graça Lobo, 279. Faro: Cineclube de Faro.

Melo Ferreira, Carlos. 2011. Cinema: Uma Arte Impura. Porto: Edições Afrontamento.

Morin, Edgar. 1980. O Cinema ou O Homem Imaginário: Ensaio de Antropologia. Tradução de António Pedro Vasconcelos. Lisboa: Moraes.

Parikka, Jussi. 2012. What is Media Archaeology? Cambridge e Malden: Polity Press.

Parks, Lisa e Starosielski, Nicole. 2015. "Introduction". Em Signal Traffic: Critical Studies of Media Infrastructures, editado por Lisa Parks e Nicole Starosielski, 1-27. Urbana: University of Illinois Press.

Peters, John Durham. 2015. The Marvelous Clouds: Toward a Philosophy of Elemental Media. Chicago e Londres: The University of Chicago Press.

Salles de Almeida, Cecília. 2008. Crítica Genética: Fundamento dos Estudos Genéticos sobre o Processo de Criação Artístico. São Paulo: Educ.

Sampaio, Sofia, Schefer, Raquel e Blank, Thaís. 2016. "Filmes utilitários, amadores, órfãos e efémeros: Repensando o cinema a partir dos 'outros filmes”. Aniki: Revista Portuguesa da Imagem em Movimento $3200-213$. https://doi.org/10.14591/aniki.v3n2.263

Starosielski, Nicole. 2015. The Undersea Network. Durham: Duke University Press.

Strauven, Wanda. 2013. "Media Archaeology: Where Film History, Media Art, and New Media (Can) Meet". Em Preserving and Exhibiting Media Art: Challenges and Perspectives, editado por 
Julia Noordegraaf, Cosetta G. Saba, Barbara Le Maître e Vinzenz Hediger, 59-79. Amsterdam: Amsterdam University Press.

Williams, Raymond. 1977. Marxism and Literature. Oxford: Oxford University Press.

\section{Analysing Materiality in Portuguese Cinema: Aesthetics and practices}

ABSTRACT Introductory text to the special section guest-edited by Caterina Cucinotta and Federico Pierotti. The authors place their contribution within the framework of the materialist turn that has been taking place, in various disciplines, in the last twenty years. They propose an approach to Portuguese cinema that pays particular attention to the concepts of materiality, film aesthetics and filmmaking practices. The five essays are presented considering the three types of materiality identified by media archaeologist Jussi Parikka: the materiality of cultural practice; the materiality of materials; and the materiality of technologies. The result is a fertile program that will ensure a future to materiality studies in Portuguese cinema.

KEYW ORDS Portuguese cinema; materiality; materialist turn; media archaeology. 